\title{
Bicycle Traffic in the Czech Republic: The Ways of Influencing the Behaviour of People Involved in It
}

\author{
Matúš Šucha ${ }^{a}$ \\ ${ }^{a}$ Palacky University in Olomouc, Czech Republic
}

ABSTRACT: The main objectives of the present paper are to provide general information about the development and safety of bicycle traffic in the Czech Republic and the ways of influencing the behaviour of road users to promote a higher share of bicycle traffic and increase the safety of cyclists. A theoretical model of influences on road users' behaviour, applied to the issue of bicycle traffic, was used for this purpose. The safety of cyclists in the Czech Republic still seems to be rather low in comparison with other developed countries of the EU (such as the Netherlands, Denmark, and Germany), where, moreover, the intensity of cycle traffic is much higher than in the Czech Republic. According to the police figures, evidence indicates that a cyclist in the Czech Republic is at a 4.5 times higher risk of being killed in a traffic accident than a cyclist in the Netherlands. An urban area must offer mobility for everybody to be a pleasant place to live. Progress in transportation means improving conditions for all modes of transport. It is not the faster, motorised modes of transport that should get priority; the emphasis should be placed on sustainability, safety, and comfort. In the Czech Republic the major barriers which prevent higher rates of cyclists in urban areas and compromise their safety include: the insufficient quality of the surfaces of cycling paths (or their absence), cycling paths not being interconnected into a coherent network, a lack of places where bicycles can be parked securely, and a lack of facilities at workplaces for people who use bicycles to get to work. However, one of the main obstacles to a higher rate of bicycles being used as means of transport is generally the cyclists' low subjective feeling of safety, especially with regard to roads used together with cars.

KEYWORDS: Bicycle Traffic; Traffic Safety; Human Behaviour; Smart Cities

\section{INTRODUCTION}

A city needs to secure mobility for everybody in order to be a pleasant place to live - it needs to be accessible and easy to get around. There are numerous groups of inhabitants, e.g. children and senior citizens, who face major restrictions in terms of their mobility. The development of transportation should involve better conditions for all modes of transport, including non-motorised ones, represented by pedestrians and cyclists.

It is undoubtedly in the interest of society as a whole to promote modes of transport such as walking, cycling, and public transport which can be regarded as socially responsible and sustainable. The use of cars, especially for short journeys within urban areas, is associated with a number of issues, such as congestion, parking difficulties, air pollution, and excessive noise. Conversely, cycling is an environmentfriendly and sustainable mode of transport with positive implications for people's health. A Dutch study (Schepers \& Heinen, 2013) disproves the negative effects of a change in the mode, i.e. from individual car transport to cycling, in terms of a higher number of road fatalities, although it does admit that the rate of injuries is likely to grow as a result of the higher share of cycling traffic.

As with virtually any kind of sport or physical activity, cycling poses some risk of injury, but studies show that the health benefits of cycling far exceed the health risks (Anderson et al., 2000).

Informed by the available evidence and practical experience, this article summarises the major obstacles that prevent the greater representation of cycling traffic in the Czech Republic and the measures that may be used to promote cycling and enhance its safety. The arguments are based on the theoretical model of influences on road users' behaviour introduced by Šucha in 2016. 


\section{THEORETICAL MODEL OF INFLUENCE ON ROAD USERS' BEHAVIOUR}

The model used to describe the ways in which people's traffic behaviour may be influenced (Figure 1) in terms of enhancing safety and using cycling as a mode of transport is practice-oriented. Its primary objective is to provide a simple, well-structured, and practical guide to the implementation of traffic safety interventions.

It builds upon the basic assumption that human behaviour is a result of people's efforts to satisfy their needs. Behaviour is thus shaped by a specific person's needs, preferences, and motivations. However, the behaviour a person engages in becomes influenced by other factors, which can be peculiar to the given individual (internal, such as their personality structure, values, and norms) or the given situation (external, such as traffic infrastructure and traffic safety campaigns). Interventions aimed at humanspecific factors in high-risk road users can be as follows: further education, training, selection, assessment, or rehabilitation. Furthermore, the model is cyclic (backwards arrow): road users' behaviour (the consequence of road users' needs) also influences (as feedback) road users' needs and preferences.

This paper focuses on situation-specific factors, i.e. those that are associated with interventions tar- geted at society as a whole (or specific segments thereof) rather than individuals. In particular, following the Diamond model (Chaloupka-Risser, Risser, $\&$ Zuzan, 2011), they are interventions delivered at the following four levels:

1. formal norms (laws), enforcement, and informal norms and culture

2. traffic infrastructure

3. means of transport that include Intelligent Transport Systems

4. mass media, campaigns, and awareness raising

\section{THE CASE STUDY: THE SITUATION IN THE CZECH REPUBLIC}

While the latest statistics in the Czech Republic (Police, 2016) suggest that the absolute figures for cycling fatalities show a declining trend (in the last 20 years) or stagnation (in the last five years), their share of the total number of fatalities remains high (68 cyclists killed in 2015), particularly when compared to the European average in countries with advanced cycling cultures (e.g. the Netherlands, Denmark, and Germany) (Safecycle, 2012). From 1993 to 2011 cyclists accounted for $9 \%$ of the total number of traffic fatalities, which means that there was one cyclist in every 11 fa-

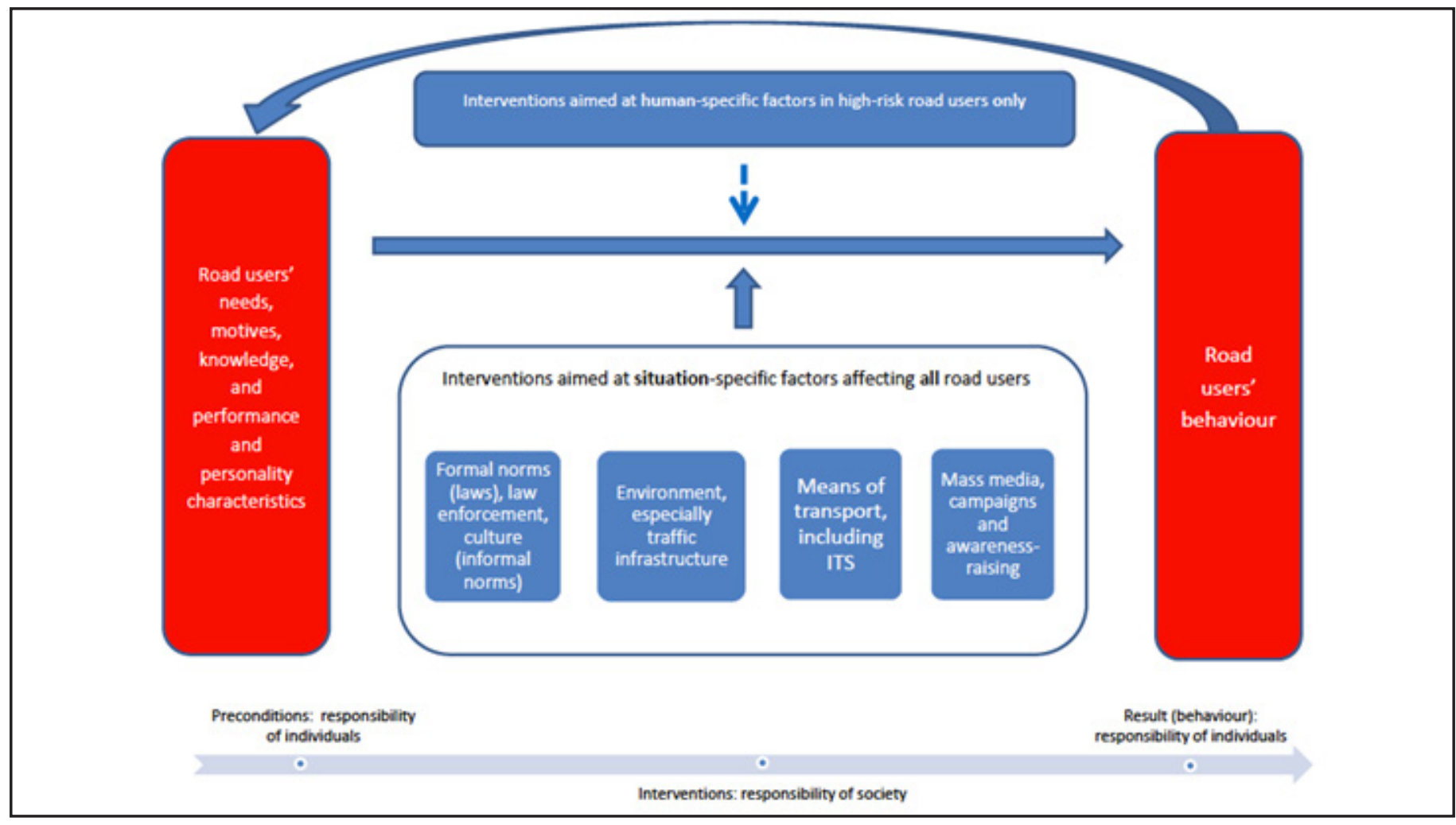

Figure 1: Theoretical model of influences on road users' behaviour (Šucha, 2016) 
talities. A cyclist in the Czech Republic is at a 4.5 times greater risk (share of cyclist fatalities according to the police records) of being killed in a traffic accident than one in the Netherlands (Cycling Strategy, 2013). The common denominator of the majority of cycling injuries is the absence of a helmet.

Frequent causes of accidents on roads with motorised traffic are (Cyclists' crashes, 2015):

- great differences in speed between cyclists and motor vehicles

- drivers (especially those of lorries) turning right have a limited view of cyclists going straight ahead or positioned on their right

- conflicts between cyclists turning left and drivers of motor vehicles behind them or oncoming

- standstill traffic-related problems (e.g. car doors being opened, manoeuvres linked to parking and driving out of a parking place)

- too little lateral clearance between a cyclist and a motor car

The key national document to promote cycling in the Czech Republic is the "Cycling Strategy" (2013). The general objective of the Cycling Strategy is to popularise bicycles in order for them to again become an equally important, natural, and integral component of urban transportation systems "on a short-distance basis", i.e. to show that bicycle traffic is competitive within five $\mathrm{km}$ distances.

The strategic objectives of the Cycling Strategy until 2020 are:

1. to scale up the share of cycling of transport capacity (measured as a percentage of all journeys) to $10 \%$ by 2020

2. to reduce the number of annual cycling fatalities and serious injuries by $50 \%$ by 2020

3. to promote the construction of high-quality and safe cycling infrastructure and the development of suitable legal conditions for the use of bicycles for both transport-related and recreational purposes.

But there are still many barriers that seem to hamper an increase in the rate of urban cyclists in the Czech Republic, in particular:

- the poor quality of the surface of cycle paths,

- sections of the cycling network not being interlinked,
- a lack of areas where bicycles can be parked safely,

- a lack of facilities for people who use bicycles to commute to work (showers, no place to leave the bicycle, etc.)

Nevertheless, the main barrier to the greater use of bicycles as a means of transport seems to be the cyclists' subjective feeling of a low level of safety, especially on roads which they share with motorists.

Czech households possess an estimated four million bicycles (a number similar to that of registered cars). Cycling accounts for $7 \%$ of the average national transport capacity. The level of the use of bicycles is increasing, especially in large cities. In Prague, for example, $29 \%$ of the respondents to a survey reported that they would use bicycles regularly if there were satisfactory conditions for that, particularly as regards safety (Cycling Strategy, 2013).

Nevertheless, the share of cycling traffic of the total transport capacity remains small. While exact mobility data, particularly that on the number of journeys made of a distance up to five to 10 kilometres, is scarce in the Czech Republic, the data available from the neighbouring countries suggests that short journeys, i.e. those up to 10 kilometres, account for about $80 \%$ of all the journeys made (KiM, 2011). It is these short journeys that offer great potential in that people could make them by bicycle (rather than by car). In the Netherlands, for example, $35 \%$ of all short journeys (up to $7.5 \mathrm{~km}$ ) are made by bicycle (Schepers \& Heinen, 2013).

\section{MEASURES TO ENHANCE CYCLING AND CYCLISTS' SAFETY IN THE CZECH REPUBLIC}

On the basis of the analysis of the current state of bicycle traffic in the Czech Republic, expert opinions, and the available literature and experience from abroad, we propose the following measures to promote cycling and cyclists' safety. The measures are divided into four areas following the above model.

\subsection{Formal norms (laws), enforcement, and informal norms and culture}

This section summarises measures that could enhance cycling and cyclists' safety with regard to the law, enforcement, and culture. When the potentially relevant legislation is being amended, the needs of bicycle traffic should always be taken into account 
too. An independent and separate approach to bicycle traffic is hardly likely to work - the process of addressing cycling must become an integral part of other documents concerning traffic operations (FHWA, 2012). The adoption of basic laws concerning the protection of cyclists must be a priority, particularly as regards the mandatory use of safety helmets for all (currently, in the Czech Republic they are only required for young people under 18). Helmets can help prevent head injuries in falls and crashes (Thompson, Rivara, \& Thompson, 1999), but laws requiring mandatory helmet use have been shown to reduce cycling among adults in Canada and Australia (Clarke, 2006). We need to exercise consistent law enforcement highlighting the equal status of drivers and cyclists. The issue of cyclists riding under the influence of drugs should receive special attention. As for the speed, lower speed limits for vehicles make cycling safer and more attractive. One study conducted in Germany found that reducing general speed limits led to a significant increase in cycling (Bauman et al., 2008). It is also important to monitor traffic accidents involving cyclists and process the data using the central register of road accidents.

All the measures should be introduced in line with local cultural customs and the bicycle traffic tradition. The Czech Republic ranks among those countries with a rather lower level of development of cycling and its having a smaller share of the overall traffic volume. Accordingly, measures taken to support the development and safety of cycling should focus on the general awareness of cycling and its benefits, as well as promoting cycling as a mode of day-to-day transport, for example, as an alternative to car use. Culturally, in the Czech Republic cycling is perceived more as a sport or a recreational activity at present.

\subsection{The environment, especially the traffic infrastructure}

The further development of the infrastructure for cyclists is needed. At the urban level, the cycling infrastructure is strongly associated with overall levels of cycling, especially with cycling to work, school, or the shops (Dill \& Carr, 2003). A study using data from 90 large U.S. cities found that cities with $10 \%$ more bike lanes or paths had about 2-3\% more daily bicycle commuters (Buehler \& Pucher, 2012). A Seattle study found that adults living within a half-mile of a bike path were $20 \%$ more likely to cycle at least once a week (Vernez-Moudon et al., 2005). Roads shared by both motor and non-motor traffic - with traffic lanes, crossings, separate paths for cyclists, the extension of $30 \mathrm{~km} / \mathrm{h}$ speed limit zones, etc. - are needed. An infrastructure that maximises the separation between cyclists and motor vehicles, without making cyclists travel too far out of their way, may be more effective in encouraging new cyclists than onstreet pavement markings (Furth, 2012). New forms of pavement markings, including bike boxes, shared lane markings ("sharrows"), and coloured bike lanes, increase perceptions of safety, help guide cyclists and motorists, and provide official, visible recognition that cyclists are legitimate users of the road (Dill, Monsere, \& McNeil, 2012). On the other hand, cycling declines with the number of stops (e.g. because of stop signs or signals) along the route, poor-quality road surfaces, and inadequate bike parking (Wardman, Tight, \& Page, 2007).

According to Leden (1999), the non-restrictive key measures which enhance cycling and should be followed in urban settings are as follows:

1 build Greenways, where any confrontation with motor traffic is practically non-existent, in green corridors without motor traffic and with grade-separated intersections, e.g. in park areas and along through traffic routes;

2 build cycle tracks along all main streets so that a cycle track runs alongside the adjacent carriageway and is elevated for its entire length.

3 gradually ensure that cars do not drive through zebra crossings at speeds above $30 \mathrm{~km} / \mathrm{h}$. If necessary, physical traffic-calming measures are to be used;

4 build special bicycle streets (Fahrradstrassen) in residential areas where priority is to be given to bicycle traffic;

5 ensure that cars cannot drive faster than $30 \mathrm{~km} / \mathrm{h}$ in all residential streets; physical traffic calming measures or speed-limiters to be used as necessary;

6 build sufficiently separated cycle tracks along all the through traffic routes used by pedestrians and cyclists;

7 build grade-separated intersections where pedestrians and cyclists cross traffic routes.

Integrating cycling with public transport increases the viability of each of them. Cycling can expand the service areas of rail transit stations and bus stops. Trains and buses, in turn, can transport cyclists over much longer distances than would be fea- 
sible by bicycle alone. Studies show that bike racks on buses and good bike parking facilities at railway stations increase both cycling and transit use (Pucher \& Buehler, 2012).

We suggest implementing measures to help in integrating cycling into the public transport system in terms of both daily commuting to work and school and cyclotourism. These include the provision of easier access to platforms and opportunities for bicycles to be parked on a Bike \& Ride basis at train, bus, and other urban public transport stops and stations, the construction of cycle parks and cycle depositories being incorporated into the building of traffic terminals, and the possibility of bicycles being transported in other means of transport (especially trains and cyclobuses).

\subsection{Bike designs and Intelligent Transport Systems}

Already available on the market, Intelligent Transport Systems seem to be of great potential with respect to cyclists' safety. According to Silla et al. (2016), the following systems were estimated to have high potential to improve the safety of cyclists: Blind Spot Detection (BSD), Bicycle-to-Vehicle communication (B2V), Intersection Safety (INS), Pedestrian and Cyclist Detection System + Emergency Braking (PCDS + EBR), and Vulnerable road users' Beacon System (VBS). An ex-ante assessment showed that all the systems that were investigated affect cyclists' safety in a positive way by preventing fatalities and injuries. The estimates considering 2012 accident data and full penetration showed that the highest effects could be obtained by the implementation of PCDS + EBR and B2V, whereas VBS had the lowest effect. The estimated yearly reduction in cyclist fatalities in the EU - 28 varied between 77 and 286 per system (Silla, Leden, Rämä, Scholliers, Van Noort \& Bell, 2016). As for bike designs, it is a must to ensure that all bicycles are sold equipped with standard safety elements, such as lights, reflectors, reflective elements, and protective devices (especially for children). Only certified (in terms of safety) bicycles should be allowed to be sold, with the age, height, and weight of the cyclist being taken into account.

Another priority should be to promote the spread and sale of electric bicycles and pedelecs - the intention being especially to provide individuals with lower physical capacities (such as older citizens and women) with an alternative to a regular bicycle. As for electric bicycles, on the other hand, it should be ensured that their maximum speed is set in such a way as to prevent any additional safety risk posed by high speed.

\subsection{Mass media, campaigns, and awareness raising}

Programmes that promote cycling may help increase the effectiveness of investments in bicycle facilities (Australian Greenhouse Office, 2005). Studies have reported long-term increases in cycling following bike-to-work days and other activities of this kind (League of American Bicyclists, 2008). Cities that have implemented bicycle-sharing programmes report substantial increases in cycling (Shaheen, Guzman, \& Zhang, 2012).

In connection with awareness raising, it is important to launch campaigns promoting the observance of traffic rules and the use of cycle lighting, helmets, and reflective elements, including campaigns intended to appeal to drivers to pay more attention to specific situations, such as children cycling to school. Furthermore, all relevant institutions (such as municipal authorities) should be provided with guidelines and consultations pertaining to bicycle traffic, including local surveys and participation in strategic meetings concerning the development of bicycle traffic.

\section{SUMMARY AND CONCLUSIONS}

Generally, research shows that infrastructure, campaigning, and policies (including laws) that are in line with cultural aspects and that support cycling can significantly increase levels of cycling for daily travel. However, it is difficult to generalise about the effectiveness of specific strategies or particular kinds of bicycle infrastructure (Pucher, Lanversin, Suzuki, \& Whitelegg, 2012). A comprehensive package of infrastructure, programmes, and policies is likely to have the greatest effect. Some cities, even very large ones, have dramatically raised cycling levels, but only thanks to a multifaceted coordinated approach that involved careful planning and ongoing input from residents (Pucher \& Buehler, 2012). To promote cycling, deterrents to driving must also be present alongside the efforts to promote cycling (Pucher \& Dijkstra, 2003). Policies that make driving more expensive (e.g. higher fuel taxes and parking fees) and less convenient (e.g. limited parking facilities and reduced speeds) may be necessary to maximise the effectiveness of infrastructure invest- 
ments in encouraging cycling. In northern Europe, the much higher cost of owning, using, and parking a car, combined with car-free zones, comprehensive traffic calming, more compact land use, lower overall speed limits, and the limited availability of parking for cars, reduces the convenience and attractiveness of car use (Pucher \& Buehler, 2008). To encourage cycling as a mode of transportation, communities must also implement land use and development policies to help ensure that destinations for daily needs, such as school, work, and shopping, are within convenient cycling distance from home.

The main challenge for Czech towns and cities is the revision of the overall perspective on urban traffic systems and, in particular, the public space. The consideration of cyclists' needs must be an integral part of the comprehensive traffic solution, as has been the case across Europe. The goal is to create urban areas which are both easy to get around and easy to get through and provide their inhabitants with good mobility. There are, however, large groups of inhabitants, including children, adolescents, and senior citizens, who are currently facing major limitations with regard to their mobility. There are still numerous towns and cities in the Czech Republic which are designed to be got around only by car, i.e. a means of transport which these individuals cannot use on their own. By making walking and cycling difficult, such areas impose limitations on the life of a considerable part of the population.

A comprehensive approach is required to bring about a more pleasant and safer life in urban areas, more effective urban mobility, cost savings, support for local businesses, a healthier environment for both inhabitants and visitors, fewer traffic congestion problems, less noise, cleaner air, the reduction of the negative impact on climate change on both a local and global scale, the saving of non-renewable natural resources, sustainable tourism, and public spaces as a venue where people can meet and interact.

Experience from abroad shows that the more cyclists and pedestrians there are on roads, the safer the roads are (the increase in the number of cyclist and pedestrian casualties is proportionately lower than that in their total numbers). The promotion of cycling is thus one of the ways to enhance safety and reduce the number of road fatalities. All we need is a new culture of urban and traffic planning which will fully respect each individual's basic right to a safe bicycle ride.

If we want to scale up the level of cycling in the Czech Republic, not only for recreational and sports purposes, but especially as a means of transport, it is necessary to implement the measures envisaged in this article. There are many examples and much empirical evidence from abroad which can be put into practice in the Czech Republic. However, cultural aspects must always be taken into account so that the measures are implemented in a way which is congruent with informal norms, customs, and the local culture in general. In order to achieve this, it is advisable to implement each measure as a pilot project first and not to proceed with its full-fledged application until the measure is assessed for its impact and modified, if needed. All measures should be properly evaluated in order to ascertain their real practical implications.

\section{LITERATURE}

Anderson, L., Schnor, P., Schroll, M., \& Hein, H. (2000). Allcause mortality associated with physical activity during leisure time, work, sports, and cycling to work. Archives of Internal Medicine. 160, 1621-1628.

Australian Greenhouse Office. (2005). Evaluation of Australian TravelSmart Projects in the ACT, South Australia, Queensland, Victoria and Western Australia: 2001-2005. Department of the Environment and Heritage.

Bauman, A., Rissel, C., Garrard, J., Kerr, I., Spiedel, R., \& Fishman, E. (2008). Getting Australia moving: Barriers, facilitators and interventions to get more Australians physically active through cycling. Funded by the Australian Government, Department of Health and Ageing. Cycling Promotion Fund, Melbourne.

Buehler, R., \& Pucher, J. (2012). Cycling to work in 90 large American cities: new evidence on the role of bike paths and lanes. Transportation. 39(2): 409-432.

Chaloupka-Risser, C., Risser, R., \& Zuzan, W. D. (2011). Verkehrspsychologie. Grundlagen und Anwendungen. facultas. wuv. Verlag, Wien Lehr U.(2000). Psychologie des Alterns, 9.

Clarke, C. (2006). The case against bicycle helmets and legislation. World Transport Policy and Practice. 12(2), 6-16.

Cycling Strategy. (2013). National cycling strategy of the Czech Republic. Retrieved from: http://www.cyklostrategie.cz.

Cyclists' crashes. (2015). Presidium of Czech Police. Retrieved on November $20^{\text {th }} 2016$ from: http://www.tymbezpecnosti.cz/ files/editor/file/nehodovost\%20cyklisté_Policie_ČR.pdf.

Dill, J., \& Carr, T. (2003). Bicycle commuting and facilities in major U.S. cities: If you build them, commuters will use them. Transportation Research Records. 1828, 116-123.

Dill, J., Monsere, C. M., \& McNeil, N. (2012). Evaluation of bike boxes at signalized intersections. Accident Analysis and Prevention. 44(1): 126-134. 
FHWA. (2012). Bicycle road safety audit guidelines and prompt list. Federal Highway Administration. FHWA final report SA-12-018. Washington, DC.

Furth, P. (2012). Bicycling infrastructure for mass bicycling: A transatlantic comparison. In: Pucher, J., \& Buehler, R. (eds.) 2012. City Cycling. MIT Press, Cambridge, Mass, 105-139.

KiM. (2011). Mobiliteitsbalans 2011. Netherlands Institute for Transport Policy Analysis, Den Haag.

League of American Bicyclists. (2008). Bike to Work events in selected US Cities. League of American Bicyclists, Washington, DC.

Leden, L. (1999). Towards Safe Non-restrictive Cycling. Traffic safety on two continents. 10th International Conference Sept 20-22, 1999 in Malmö, Sweden. Swedish National Road and Transport Research Institute, US Transportation Research Board, Bundesanstalt für Strassenwesen. VTI conferens 13 A part 5, Vulnerable Road Users.

Police of the Czech Republic. (2016). Traffic safety indicators. Retrieved on November $20^{\text {th }} 2016$ from: http://www.policie.cz/ clanek/statistika-nehodovosti-178464.aspx.

Pucher, J., \& Buehler, R. (2008). Making cycling irresistible: Lessons from the Netherlands, Denmark, and Germany. Transport Reviews. 28(4), 495-528.

Pucher, J., \& Buehler, R. (2012). Integration of cycling with public transportation. In: Pucher. J. \& Buehler, R., eds. City Cycling, MIT Press, Cambridge, Mass., 157-181.

Pucher, J., \& Dijkstra, L. (2003). Promoting safe walking and cycling to improve public health: Lessons from the Netherlands and Germany. American Journal of Public Health, 93(9), 1509-1516.

Pucher, J., \& Buehler, R. (2012). Promoting cycling for daily travel: Conclusions and lessons from across the globe. In: Pucher, J. \& Buehler, R. (eds.) 2012. City Cycling. MIT Press, Cambridge, Mass, 347-363.

Pucher, J., Lanversin, E., Suzuki, T., \& Whitelegg, J. (2012). Cycling in megacities: London, Paris, New York, and Tokyo. In: Pucher, J. \& Buehler, R. (eds.) 2012. City Cycling. MIT Press, Cambridge, Mass, 319-345.

Safecycle. (2012). Safecycle final report. Retrieved on November $20^{\text {th }} 2016$ from: http://www.safecycle.eu.

Schepers, J. P., \& Heinen, E. (2013). How does a modal shift from short car trips to cycling affect road safety? Accident Analysis and Prevention, 50, 1118-1127.

Shaheen, S., Guzman, S., \& Zhang, H. (2012). Bikesharing across the globe. In: Pucher, J., \& Buehler, R. (eds). City Cycling. MIT Press, Cambridge, Mass, 183-209.

Silla, A., Leden, L., Rämä, P., Scholliers, J., Van Noort, M., \& Bell, D. (2016). Can cyclist safety be improved with intelligent transport systems? Accident Analysis and Prevention http://dx.doi.org/10.1016/j.aap.2016.05.003.

Šucha, M. (2016). Možnosti ovlivnění chování účastníků silničního provozu. Silniční obzor, 5.
Thompson, D. C., Rivara, F. P., \& Thompson, R. (1999). Helmets for preventing head and facial injuries in bicyclists. Cochrane database of systematic reviews, 4. Retrieved from: http://onlinelibrary.wiley.com/wol1/doi/10.1002/14651858. CD001855/full.

Vernez-Moudon, A. V., Lee, C., Cheadle, A. D., et al. (2005). Cycling and the built environment, a US perspective. Transportation Research Part D. 10, 245-261.

Wardman, M., Tight, M., \& Page, M. (2007). Factors influencing the propensity to cycle to work. Transportation Research Part A. 41, 339-350. 